Fajar Historia: Jurnal Ilmu Sejarah dan Pendidikan

Volume 2 nomor 2, Desember 2018, Hal. 46 - 58

\title{
LEMBAGA ADAT PASITABE DI KABUPATEN LUWU TIMUR
}

(1992-2011)

\author{
${ }^{1}$ KULYASIN \\ ${ }^{1}$ Universitas Negeri Makassar \\ @kulyasin.92@gmail.com
}

\begin{abstract}
Based on the results of the study showed that the Pasitabe Customary Institution was born as a result of the upheaval that occurred in South Sulawesi. In the decade 50 to 60 which made conditions and situations very unsafe for some people of South Sulawesi, especially in Tana Luwu, most of the people consisted of sub-ethnic . For this reason, the sub ethnic groups in Tana Luwu also referred to the Padoe Tribe, Karunsi'e and Tambe'e exodus to other places. A series of meetings have been held to achieve the goal of forming a unitary group between the Padoe, karunsi'e, and Tambe tribes, namely in 1962 in Taliwan, the second meeting in 1984 in Pakatan and the third meeting took place in Wawondula in the same year as the establishment of the Institute Pasitabe custom formally by consensus. The development period of the Pasitabe Customary Institution began itself in 1992 where this year Pasitabe has officially declared itself as an Adat Institution, and cultural preservation that has been carried out to date provides positive results by giving education to the younger generation and always making it an ancestral civilization should be guarded. Pasitabe Customary Institutions influence several aspects of life, both social, cultural and political, in the social aspect Pasitabe has succeeded in restoring indigenous peoples' selfconfidence. Culture and customary re-living and enthusiasm in participating in politics are very large. Because based on the findings that have been obtained, it is suggested that the government pay more attention to what customary institutions are better related to communal land and local cultural preservation.
\end{abstract}

Keywords: Customary Institutions, Pasitabe, Cultural Impacts, Social, Politics

\section{Astrak}

Berdasarkan hasil penelitian menunjukan bahwa Lembaga Adat Pasitabe lahir sebagai akibat dari pergolakan yang terjadi di Sulawesi Selatan Pada dekade 50 hingga 60 yang membuat kondisi dan situasi sangat tidak aman bagi sebagian masyarakat Sulawesi Selatan khususnya di Tana Luwu yang sebagian besar masyarakatnya terdiri dari sub-sub etnis. Dengan alasan inilah kemudian sub etnis yang berada di Tana Luwu termaksud juga Suku Padoe, Karunsi'e danTambe'e eksodus ke tempat lain. Rangkaian pertemuan telah dilakukan untuk demi tercapainya tujuan membentuk kelompok kesatuan antara Suku Padoe, karunsi'e, dan Suku Tambe'eyaitu pada tahun 1962 di Taliwan, pertemuan kedua 
pada tahun 1984 di Pakatan dan pertemuan ketiga terjadi di Wawondula pada tahun sekaligus sebagai tahun terbentuknya Lembaga Adat Pasitabe secara resmi dengan jalan musyawarah mufakat. Masa perkembangan Lembaga Adat Pasitabe dimulai diri tahun 1992 dimana di tahun ini Pasitabe telah resmi mendeklarasikan diri sebagai sebuah Lembaga Adat kemudian pelestarian budaya yang dilakukan hingga saat ini memberikan hasil yang positif dengan cara memberi pendidikan kepada generasi muda serta selalu menjadikannya sebagai sebuah peradaban nenek moyang yang semestinya dijaga. Lembaga Adat Pasitabe memberi pengaruh pada beberapa aspek kehidupan baik sosial, budaya dan politik, dalam aspek sosial Pasitabe telah berhasil mengembalikan kepercayaan diri masyarakat adat.Budaya dan adat istiadat kembali lestari dan antusias dalam berpartisipasi politik pun sangat besar. Karena berdasarkan hasil temuan yang telah diperoleh disarankan agar pemerintah lebih memperhatikan lembaga adat dengan baik apa lagi terkait dengan tanah ulayat dan pelestarian budaya setempat.

Kata Kunci:Lembaga Adat, Pasitabe, Dampak Budaya, sosial, Politik

\section{PENDAHULUAN}

Periode terpenting dalam sejarah Sulawesi Selatan membuat peranan kerajaan-kerajaan yang pernah menjadi penguasa di tanah Sulawesi seperti Kerajaan Luwu, Kerajaan Gowa, serta Kerajaan Bone, secara arif menjadikannya identitas terluas suatukebudayaan yang hakiki lestari hingga saat ini di Propinsi Sulawesi Selatan, serta menjadi cikal bakal munculnya sub etnis penghuni daratan Sulawesi. Sulawesi Selatan memiliki banyak sekali keragaman budaya, adat istiadat, serta nilai-nilai budaya yang luhur dan sangat kompleks, diantaranya diketahui ada beberapa Suku besar yang diwarisi oleh cerita panjang sejarah Sulawesi Selatan mendominasi di seluruh daratanSulawesi Selatan yaitu Suku Bugis, Suku Mandar, SukuMakassar, dan Suku Toraja yang masing- masing memiliki daerah pemukimannya tersendiri.

Bagi masyarakat Sulawesi Selatan sangat tidak asing lagi mendengar nama keempat Suku di atas, cerita bersejarahnya, budaya, serta adat istiadat yang dimiliki sangatlah sering terdengar. Sangat banyak karya tulis ilmiah yang menceritakan tentang kearifan lokal dari keempat Suku tersebut, baik dijadikan rujukan penelitian, pengetahuan umum, bahkan digunakan juga sebagiarujukukan akademik di institusi-institusi penyelenggara pendidikan. Inilah yang kemudian membuat eksistensi mereka masih tetap terjaga hingga saat ini. 
Keempat Suku dominan tersebut dengan cerita bersejarahnya di Jazirah Sulawesi Selatan serta upaya pelestarian dan mempertahankan eksistensinya yang membuat lupa bahwa masih ada banyak sub etnis lain mendiami daratan Sulawesi Selatan, pengaruhnya pun tidak kalah penting terhadap kerajaan-kerajaan besar yang ada di Sulawesi Selatan, dan sangat jarang termuat dalam karya-karya tulis sejarah lokal Sulawesi Selatan.

Beberapa suku yang dimaksud adalah Suku Padoe, Suku Karunsie, dan Suku Tambee dimana ketiga Suku tersebut berada di Kabupaten Luwu Timur secara historis dahulu masuk dalam wilayah Kerajaan Luwu. Banyak cerita yang beredar dari mulut kemulut di masyarakat Luwu Timur tentang peran dari ketiga Suku tersebut dalam upaya membantu Kerajaan Luwu, salah satunya adalah cerita jasa-jasa para pasukan perang Suku Padoe yaitu pongkari membantu Kerajaan Luwu dalam setiap peperangan melawan penjajahan di Tanah Luwu. Dari banyaknya sub etnis yang ada di Luwu Timur hanya beberapa sub etnis yang mampu mempertahankan kebudayaannya hingga saat ini termasuk ketiga Suku yang peneliti sebutkan di atas, bahkan ada beberapa sub etnis yang musnah dan menghilang baik karena faktor modernisasi ataupun faktor konflik yang terjadi di wilayah tersebut. Contoh yang terjadi pada salah satu Suku yang mendiami Desa Matano di Kabupaten Luwu Timur. Menurut beberapa sumber Suku yang mendiami Desa Matano pada abad 14 ini memiliki peradaban yang sangat tinggi dengan ciri khas sebagai Suku pandai besi, namun karena tidak mampunya Kerajaan Luwu bersaing dengan Bangsa Belanda dalam hal perdagangan, dimana perdagangan pada saat itu tidak lagi menjadikan besi sebagai komoditas utama melainkan rempah-rempah lah yang menjadi buruan utama para pedagang menjadikan Suku pandai besi ini menghentikan produksi senjata serta peralatan lain yang terbuat dari besi.

Sejarah pergolakan yang terjadi di Sulawesi pada dekade 50 hingga 60-an, yang didalangi oleh DI-TII dan Permesta, membuat wilayah Sulawesi cukup porak-poranda, baik tatanan sosial, ekonomi maupun infrastrukturnya. Tak sedikit kelompok masyarakat yang harus eksodus dari kampung halamannya; lari menyelamatkan diri ke hutan-hutan atau ke kampung lain, bahkan menyeberang hingga ke lain provinsi.(Harvey. 1973) 
Etnis Padoe, Karunsie dan Tambee pun terkena dampak pergolakan tersebut. Tragedi telah merubah hampir keseluruhan tatanan masyarakat baik ekonomi, budaya, sosial serta adat istiadat Suku-Suku yang mendiami Luwu Timur yang selama berabad-abad mereka jaga sebagai pengontrol tingkah laku serta tuntunan dalam menjalani kehidupan bermasyarakat.

Ketika masa telah aman, pada akhir 60-an hingga awal 70-an, terjadilah arus balik ke Tanah Nuha. Etnis Padoe, Karunsie dan Tambee kini menemukan kampung mereka telah berubah oleh pergolakan yang panjang. Sawah dan ladang hancur tak terurus, lumbung penyimpanan padi habis terkuras, rumah pun lenyap terbakar, bahkan sejumlah sanak saudara tak lagi dapat ditemukan karena menjadi korban pergolakan. Tak banyak yang tersisa, semua hilang dan lenyap.Termasuk semangat dan keberanian yang pernah ada.

Memang tak mudah untuk membangun kembali apa yang telah hancur. Dibutuhkan waktu bertahun-tahun untuk memompa semangat agar bangkit dari kehancuran.Dibutuhkan waktu pula untuk menata kembali jajaran persawahan, ladang dan perkebunan yang perlahan telah berubah menjadi hutan.Bertahun juga untuk memelihara dan membiakkan kembali ternak dan unggas yang pernah ada.

Rumah dan pakaian adat telah habis terbakar.Yang tersisa pun telah lapuk dimakan masa.Sungguh tak banyak yang tersisa.Hanya nyanyian tentang kampung halaman dan tarian syukur yang mengiringinya. Tak banyak yang tertinggal, selain ingatan akan irama tabuhan gendang dan gong yang pun tak serta merta dapat dimainkan karena gong dan gendang itu telah tercecer di hutan saat menyelamatkan diri.

Masuknya Industri ke Kabupaten Luwu Timur pada tahun 1968 juga menjadi masalah yang cukup krusial bagi masyarakat adat anak suku yang di Kabupaten Luwu Timur, sejak kemunculannya menimbulkan berbagai masalah yang melibatkan masyarakat adat yang ada di Kabupaten Luwu Timur.PT. INCO adalah singkatan dari Perseroan Terbatas International Nickel Indonesia. Keberadaan PT. INCO dimulai pada tahun 1967 ketika International Nickel Company of Canada yaitu salah satu perusahaan penghasil nikel di dunia yang memberi jawaban atas undangan pemerintah Indonesia untuk mengajukan penawaran, dalam rangka melakukan eksplorasi dan mengembangkan endapan biji nikel 
lateriat di Sulawesi. Pada tahun 1968 PT. INCO terpilih dan diminta merundingkan suatu kontrak karya dengan pemerintah Indonesia (Kasman. 1998: 11).

Berbagai konflik yang terjadi antara masyarakat adat dengan pihak PT. INCO dalam memperebutkan tanah ulayat menimbulkan kegelisahan yang amat mengganggu bagi seluruh anak suku yang ada di Kabupaten Luwu Timur. Kegelisahan serta rasa senasib dan penderitaan yang sama yang disebakan oleh pergolakan panjang DI/TII dan eksplorasi yang dilakukan PT. INCO terhadap Tanah Adat membuat beberapa masyarakat suku di Kabupaten Luwu Timur berupaya untuk bangkit dan menyatukan kekuatan.

\section{METODE PENELITIAN}

Pendekatan penelitian yang digunakan dalam penelitian ini adalah penelitian kulaitatif, sedangkan metode penelitian yang digunakan adalah metode sejarah. Metode sejarah menekankan pada kejelasan adanya batasan waktu dan tempat yang dalam penelitian ini bertempat di Lembaga Kedatuan Luwu antara tahun 1992-2011. Adapun alur metode dalam penelitian sejarah dilakukan mulai dari heuristik (pengumpulan data baik berupa dokumen dan sejarah lisan), kritik, interpretasi, dan historiografi.

\section{HASIL PENELITIAN}

\section{A. Latar Belakang Terbentuknya Lembaga Adat PASITABE}

Kejayaan yang dimiliki Kerajaan Luwu dahulu hingga sekarang tidak terlepas dari peristiwa- peristiwa penting baik pada bidang politik, ekonomi dan budaya, maka dari itu kiranya penting untuk dikaitkan dengan latar belakang terbentuknya Lembaga Adat Pasitabe di Kabupaten Luwu Timur karena ada peristiwa yang terjadi di Tana Luwu pada dekade 50an yang erat kaitannya dengan cikal- bakal terbentuknya Lembaga Adat Pasitabe.

Perjalanan panjang sejarah Kerajaan Luwu dari abad VIII sampai pada Luwu dewasa ini membawa penulis memfokuskan pada kondisi Luwu dekade 50an yang menempatkan Luwu dalam suatu kondisi pergolakan akibat dinamika politik yang terjadi. Pada dekade tahun tersebut rangkaian-rangkaian cerita serta dinamika yang terjadi didalam 
batang tubuh KedatuanLuwu menjadi suatu hal yang menarik untuk di bahas dalam karya ini, karena peristiwa yang terjadi pada Tana Luwu berimbas pula pada keteraturan tatanan masyarakat adat yang berada di wilayah naungan Kerajaan Luwu, dalam hal ini adalah masyarakat 12 suku adat yang selama berabad-abad telah memiliki hubungan yang baik dengan Kerajaan Luwu.

Pada pidato kemerdekaan yang tahun 1952 yang digelar di lapangan Timampu( sekarang Kecamatan Towuti ). Saat itu seorang pasukan DI/TII membacakan pidato dengan semangat yang berapi-api. Pada pidato tersebut berisikan pengumuman yang membuat penganut Agama selain Islam menjadi merinding ketika mendengarkannya ( Sepenggal pidato yang masih tersimpan dalam ingatan narasumber yaitu Thomas Lasampa sebagai berikut: “ Kalau ada yang memelihara babi diberi kesempatan seminggu untuk pulang dan membantai babinya. Setelah itu semua harus masuk islam ( isi pengumuman yang ditirukan oleh narasumber)” ( wawancara dengan Thomas Lasampa pada 26 Maret 2018).

\section{B. Perkembangan Lembaga Adat Pasitabe dalam kurun waktu 1992-2011}

1. Periode Awal 1992-2001

Perjalanan panjang yang ditempuh Lembaga Adat Paitabe untuk membuat keteraturan kembali seperti sedia kala.Peursen (1988: 18) mengatakan Kebudayaan dewasa ini dipengaruhi olehsuatu perkembangan yang pesat dan manusia modern sadar akan hal ini. Lebih daridulu manusia dewasa ini sadar akan kebudayaannya. Kesadaran ini merupakan suatukepekaan yang mendorong manusia agar dia secara kritis menilai kebudayaan yangsedang berlangsung. Sehingga kesadaran Masyarakat Suku Padoe, Karunsi'e dan Tambe,e harus semestinya berkembang dan kristis menilai kebudayaannya agar keberlangsungan kebudayaan yang mereka milik tetap terjaga dengan baik.

Segala upaya telah dilakukan hingga terbentuknya sebuah lembaga pemersatu yaitu Pasitabe bukan berarti tak mengalami kendala dalam perkembangannya Mempererat kerukunan, kebersamaan, persatuan dan kesatuan, koordinasi dan komunikasi masyarakat Suku Padoe, Karunsi'e dan Tambe'e. Awal terbentuk pada tahun 1992 secara resmi telah disepakati didalam musyawarah pertama yang diadakan oleh para generasi Suku Padoe, 
Karunsi'e dan Tambe'e yang membentuk sebuah lembaga persatuan yang dinamakan Pasitabe singkatan dari ketiga nama suku yang telah lama mendiami Tanah Nuha yaitu Padoe, Karunsi'e, Tambe'e (PASITABE), terbentuknya Lembaga Adat ini merupakan fase yang berpengaruh bagi kelangsungan budaya dari ketiga suku ini dan juga lembaga adat ini adalah roh baru bagi masyarakat suku yang tengah di rundung rasa putus asa yang sangat besar di karenakan kondisi buruk yang dialami.

Pada awal perkembangannya Lembaga Adat Pasitabe diterima dengan sangat baik ditengah masyarakat adat, antusias yang sangat besar ditunjukan oleh masyarakat adat dari ketiga suku ini, berkat semangat serta antusias masyarakat adat mengantarkan Lembaga Adat Pasitabe menuju pada perkembangan yang signifikan. Gotong royongpun mulai di galangkan untuk mula-mula membenahi kampung kelahirannya yang telah rusak, serta upaya mengembalikan kesenian serta tradisi juga mulai di sosialisasikan, seperti yang diungkapkan oleh MartinusTomana;

"Kami mulai gotong royong membangun kembali kampung kami yang rusak, mengumpulkan yang masih bisa dipakai, lalu kami juga mulai menarikan kembali tari-tarian kami dan kami juga membuat kembali alat musik kami yang sebelumya hilang" ( wawancaraMartinusTomani Pada tanggal 27 maret 2018).

Upaya ini terus dilakukan sepanjang tahun dan mulai menyelenggarakan pesta kesenian yang hingga saat ini masih terus dilakukan.Disisi lain ketika Lembaga Pasitabe mulai menemukan kekuatannya ternyata masalah juga datang seiring kembalinya masyarakat adat suku ke kampung halamannya yaitu masuknya perusahaan tambang pada tahun 1968 menjadi problem baru bagi masyarakat Pasitabe terkhusus pada masyarakat Suku Karunsi'e yang bermukim di Kampung Dongi, Menurut data Badan Pusat Statistik tahun 2017 (2017: 07). Kampung Dongi terletak di wilayah Administrasi Desa MaganiKec.Nuha Kecamatan Nuha berada pada posisi $2^{\circ} 18^{\prime} 00^{\prime}$ - $2^{\circ} 39^{\prime} 00^{\prime}$ Lintang Selatan dan $121^{\circ} 3$ '00" - $121^{\circ} 34^{\prime}$ 30" Bujur Timur dengan luas wilayah 808,27 km2, Kab. Luwu Timur, yang berubah status menjadi Kelurahan Magani sejak Pemerintah Kabupaten Luwu Timur mengeluarkan Peraturan Daerah (PERDA) Nomor 24 Tahun 2011 tentang Perubahan Status Desa Magani Menjadi Kelurahan Magani Kecamatan NuhaKabLuwu 
Timur. Masalah ini terjadi ditandai dengan dikeluarkannya izin eksplorasi tambang oleh pemerintah terhadap PT. INCO pada tahun 1968 yang notabene berada pada wilayah adat (Abdul Rahman Nur, 2014: 01).Hal ini yang kemudian mempengaruhi perubahan sosial masyarakat Suku Padoe, Karunsi'edan Tambe'e yang baru saja kembali ke kampung halamannya pasca pergolakan yang terjadi.Durkheim menjelaskan bahwa perubahanperubahan kehidupan masyarakat yang diakibatkan dari keberadaan perusahaan tambang ini dapat dikategorikan perubahan masyarakat agraris (primitif) menjadi masyarakat industri. (Durkheim dalam Martono, 2011: 42).Segala upaya sudah dilakukan oleh Lembaga Adat Pasitabe untuk membantu menyelesaikan masalah ini namun hingga saat ini masalah belum terselesaikan.

\section{Dampak Yang Ditimbulkan dengan Adanya Lembaga AdatPasitabeBagi Kehidupan Masyarakat Sosial, Budaya dan Politik Di Kabupaten Luwu Timur}

Keberadaan Lembaga Adat Pasitabe sebagai sebuah wadah pemersatu bagi masyarakat Suku Padoe, Karunsi'e dan Tambe'e pada tahun 1992 sampaitahun 2011, pada hakekatnya telah mengukir perjalanan sejarah yang begitu panjang sehingga dampak yang ditimbulkan bagi masyarakat dari ketiga suku tersebut sangatlah kompleks, salah satunya pada aspek sosial, budaya, dan politik.Lembaga Adat Pasitabe yang memiliki tujuan untuk melestarikan budaya, adat istiadat serta kearifan lokal Suku Padoe, Karunsi'e dan Tambe'e merupakan langkah besar yang diambil oleh generasi terdahulu sebagai reaksi akibat peristiwa pergolakan yang terjadi di tanah nenek moyangnya. Perubahan dalam aspek budaya, sosial dan politik sangat jelas terlihat akibat pergolakan tersebut, maka dari itu Lembaga Adat Pasitabe memiliki dampak yang besar bagi pembenahan kondisi yang telah berubah baik dari aspek budaya, sosial, dan politik.

Dampak adalah pengaruh kuat yang mendatangkan akibat baiknegatif maupun positif (Pusat Bahasa Departemen Pendidikan Nasional, 2001: 234).Kata Dampak dalam penulisan ini memberi pengertian berupapengaruh kuat yang mendatangkan akibat positif.Dalam pengaruh yang di timbulkan dengan adanya Lembaga Adat Pasitabe dari tahun 1992 sampai tahun 2011. 


\section{Pasitabe Sebagai Perekat Hubungan Sosial}

Dalam Kamus Besar Bahasa Indonesia (KBBI) dijelaskan bahwa Pengaruh atau akibat dari suatu kejadian, keadaan, kebijakan sehingga mengakibatkan perubahan baik yang bersifat positif maupun yang bersifat negatif bagi lingkungan sosial dan keadaan sosial.Sesuai dengan tujuan terbentuknya Lembaga Adat Pasitabe yaitu mengembalikan kembali nilai-nilai kearifan lokal adat, budaya dari Suku Padoe, Karunsi'e dan Tambe'e tentunya berakibat juga pada kondisi sosial masyarakat Lembaga Adat Pasitabe.

Dampak positif yang ditimbulkan dengan adanya Lembaga Adat Pasitabe ini bagi masyarakat Suku Padoe, Karunsi'e dan Tambe'e ialah semakin eratnya hubungan kekeluargaan yang terjalin antara mereka pasca peristiwa yang mereka anggap kelam menimpa tanah kelahirannya, hal ini secara otomatis meminimalisir pertikaian yang kemungkinan terjadi diantara mereka, terbukti dengan diadakannya pekan kesenian, budaya, dan olahraga secara rutin setiap tahunya menjadi bukti bahwa rasa kekeluargaan mereka yang tinggi.

\section{Pasitabe Sebagai Pelestari Budaya}

Kebudayaan adalah suatu cara hidup yang berkembang dan dimiliki bersama oleh sebuah kelompok orang dan diwariskan dari generasi ke generasi.Budaya terbentuk dari banyak unsur yang rumit, termasuk sistem agama dan politik, adat istiadat, bahasa, perkakas, pakaian, bangunan, dan karya seni. C. Geertz ( HariPoerwanto. 2010: 58) berpendapat bahwa kebudayaan adalah sistem pemaknaan yang dimiliki bersama, dan kebudayaan merupakan hasil dari proses sosial yang dilakukan oleh manusia dan bukan dari hasil dari proses yang dilakukan oleh perseorangan. Pemaknaan dalam proses kehidupan sosial manusia dimuka bumi ini harus bersifat kolektif, maka dari itu peran kelompok- kelompok manusia sosial sangat diperlukan agar proses kehidupan manusia berjalan sesuai dengan nilai-nilai kebudayaan.

Budaya yang dimiliki ketiga suku yang tergabung dalam Lembaga Adat Pasitabe yang notabene diwarisi oleh para leluhur dari turun- temurun pernah mengalami kondisi yang cukup memprihatinkan akibat pergolakan yang terjadi dahulu, meliputi kesenian, tradisi, tatanan masyarakat, serta bahasa maka dari itu terbentuknya Lembaga Adat 
Pasitabe ini bertujuan untuk mengembalikan kebudayaan yang pernah hilang kembali seperti sedia kala seperti ketika pergolakan belum terjadi di tanah kelahirannya. Berikut menurut hasil analisis penulis dan beberapa potongan wawancara dengan narasumber maka dapat di simpulkan dampak yang ditimbulkan dengan adanya Lembaga Adat Pasitabe dalam aspek budaya.

\section{Pasitabe dalam Berdemokrasi}

Sejak awal hingga perkembangan yang terakhir, Lembaga Adat Pasitabe bukan hanya mempengaruhi pada aspek sosial dan budaya saja melainkan pada aspek politik pun Lembaga Adat Pasitabe memiliki peranan yang cukup aktif apa lagi pada saat pesta demokrasi Nasional di selenggarakan. Namun sebelum lebih jauh membahas mengenai dampak Lembaga Adat Pasitabe pada aspek politik maka penulis akan membahas terlebih dahulu sekilas mengenai politik, berikut beberapa definisi politik menurut beberapa sumber.

Ada sekurang- kurangnya lima pandangan mengenai politik. Pertama, politik ialah usaha-usaha yang ditempuh warga negara untuk membicarakan dan mewujudkan kebaikan bersama.Kedua, politik ialah segala hal yang berkaitan dengan penyelenggaraan negara dan pemerintah.Ketiga, politik sebagai segala kegiatan yang diarahkan untuk mencari dan mempertahankan kekuasaan dalam masyarakat.Keempat, politik sebagai kegiatan yang berkaitan dengan perumusan dan pelaksanaan kebijakan umum. Kelima, politik sebagai konflik dalam rangka mencari dan/atau mempertahankan sumber-sumber yang dianggap penting (RamlanSubakti, 1992 : 1-2).

\section{PENUTUP}

1. Lembaga Adat Pasitabe lahir sebagai akibat dari pergolakan yang terjadi di Sulawesi Selatan Pada dekade 50 hingga 60 yang membuat kondisi dan situasi sangat tidak aman bagi sebagian masyarakat Sulawesi Selatan khususnya di Tana Luwu yang sebagian besar masyarakatnya terdiri dari sub-sub etnis yang sejak lama telah menghuni daerah ini. Dengan alasan inilah kemudian sub etnis yang berada di Tana Luwu termaksud juga SukuPadoe, Karunsi'e dan Tambe'e eksodus ke tempat lain 
demi menyelamatkan hidup dan ideologinya, masyarakat Suku yang eksodus keberbagai tempat mencoba menginisiasi diri untuk membentuk sebuah perkumpulan dengan tujuan menjaga perpecahan di antara mereka dan juga mencegah punahnya budaya serta adat istiadat yang telah lama mereka jadikan sebagai pedoman hidup secara turun temurun. Rangkaian pertemuan telah dilakukan untuk demi tercapainya tujuan membentuk kelompok kesatuan antara Suku Padoe, karunsi'e, dan Suku Tambe'e yaitu pada tahun 1962 di Pakatan, pertemuan kedua pada tahun 1984 di Taliwan Provinsi Sulawesi Tengah dan pertemuan ketiga terjadi di Wawondula pada tahun 1992 sekaligus sebagai tahun terbentuknya Lembaga Adat Pasitabe secara resmi dengan jalan musyawarah mufakat.

2. segala upaya telah dilakukan hingga terbentuknya sebuah lembaga pemersatu yaitu Pasitabebukan berarti tak mengalami kendala dalam perkembangannya Mempererat kerukunan, kebersamaan, persatuan dan kesatuan, koordinasi dan komunikasi masyarakat Suku Padoe, Karunsi'e dan Tambe'e. Awal terbentuk pada tahun 1992 secara resmi telah disepakati didalam musyawarah pertama yang diadakan oleh para generasi Suku Padoe, Karunsi'e dan Tambe'e yang membentuk sebuah lembaga persatuan yang dinamakan Pasitabesingkatan dari ketiga nama suku yang telah lama mendiami Tanah Nuha yaitu Padoe, Karunsi'e, Tambe'e (PASITABE), terbentuknya Lembaga Adat ini merupakan fase yang berpengaruh bagi kelangsungan budaya dari ketiga suku ini dan juga lembaga adat ini adalah roh baru bagi masyarakat suku yang tengah di rundung rasa putus asa yang sangat besar di karenakan kondisi buruk yang dialami. Pada awal perkembangannya Lembaga Adat Pasitabediterima dengan sangat baik ditengah masyarakat adat, antusias yang sangat besar ditunjukan oleh masyarakat adat dari ketiga suku ini, berkat semangat serta antusias masyarakat adat mengantarkan Lembaga Adat Pasitabemenuju pada perkembangan yang signifikan. Pada saat musyawarah pertama Lembaga Adat Pasitabe di tahun 1992 juga telah menetapkan 3 wilayah perwakilan Lembaga Adat Pasitabe yakni Kecamatan Nuha sebagai pusat Pasitabe, kemudian Pakatan sebagai wilayah perwakilan ke II dan Taliwan sebagai wilayah perwakilan ke III. Musyawarah kedua tahun 2004 dibentuk wilayah 
perwakilan ke 4 sampai wilayah ke 9. Tahun 2011 adalah Tahun dimana Lembaga Adat Pasitabemelakukan Musyawarah ketiga, seperti halnya musyawarah yang telah dilakukan sebelumnya pada musyawarah di tahun ini juga memutuskan perubahan ketua umum Lembaga Adat Pasitabeserta perumusan program yang akan dilakukan kedepan terkait pelestarian Budaya dan Adat istiadat, hal yang membedakan dengan musyawarah yang lalu ialah pada musyawarah di tahun 2001 ini Lembaga Adat Pasitaberesmi diakui secara de fakto.

3. Lembaga Adat Pasitabe telah melakukan upaya untuk mengembalikan kembali kondisi sosial yang semestinya terjalin antar masyarakat Suku Padoe, Karunsi'e dan Tambe’e. Budaya yang dimiliki ketiga suku yang tergabung dalam Lembaga Adat Pasitabe yang notabene diwarisi oleh para leluhur dari turun- temurun pernah mengalami kondisi yang cukup memprihatinkan akibat pergolakan yang terjadi dahulu, meliputi kesenian, tradisi, tatanan masyarakat, serta bahasa maka dari itu terbentuknya Lembaga Adat Pasitabeini bertujuan untuk mengembalikan kebudayaan yang pernah hilang kembali seperti sedia kala seperti ketika pergolakan belum terjadi di tanah kelahirannya. Bahasa dan Tari Tradisonal mampu dikembalikan oleh Lembaga AdatPasitabe.

\section{DAFTAR PUSTAKA}

Abdurrahman, Dudung. 2011. Metode Penelitian Sejarah Islam. Yogyakarta: Ombak

Budihardjo, Andreas. 2011. Organisasi: Menuju Pencapaian Kinerja Optimum. Jakarta: PrasetyaMulya Publishing

Daliman, 2012.Metode Penelitian Sejarah. Yogyakarta: Ombak

Gottschalk, Louis. 1985. Mengerti Sejarah. Jakarta: UI press

Gultom, Hetty. 2013. Konsorsium Perpustakaan di Indonesia. Medan: Perpustakaan Universitas Sumatera Utara

Harvey, Barbara Silar. 1973. PemberontakanKaharMuzakar Dari Tradisi ke DI/TII. Jakarta: Garfitipres

Helius, Sjamsuddin. 2007. Metodologi Sejarah. Jakarta: Ombak 1994. Metodologi Sejarah. Jakarta: Departemen Pendidikan dan

Jenks, Crhis. 1993. Culture SstudiKebudayaan. Yogyakarta: Pustaka Pelajar Kartono, Kartini. 1990. Pengantar Metodologi Riset Sosial. Bandung: Mandar Maju Koentjaraningrat, 1977.Metode- Metode Penelitian Masyarakat. Jakarta: P.T Gramedia 
1986. Pengantar Ilmu Antropologi. Jakarta: Rineka

Kuntowijoyo. 1995. Pengantar Ilmu Sejarah. Yogyakarta: Yayasan Bentang Budaya

lmaKesuma, Andi. 2015.Legacy Tana Luwu. Dinas Kebudayaan dan KepariwisataanProvinsi Sulawesi Selatan

Mattulada.1997. Kebudayaan, Kemanusiaan, dan Lingkungan Hidup. Ujung Pandang: Lembaga Penerbit Universitas Hasanuddin

Muhyadi. 2012. Dinamika Organisasi (Konsep dan Aplikasinya Dalam Interaksi Sosial. Yogyakarta: Ombak

Nasution, Muhammad SyukriAlbani, dkk. 2015. Ilmu Sosial Budaya Dasar. Jakarta: Rajawali Pers

Nawawi,Hadari.1998. Metode Penelitian Bidang Sosial. Yogyakarta: Gadjah Mada University Press

Notosusanto, Nugroho. 1978. Masalah Penelitian Sejarah Kontemporer. Jakarta: Yayasan Idayu

Puerwanto Hari.2010. Kebudayaan dan Lingkungan Dalam Perspektif antropologi. Yogyakarta: pustaka pelajar

SjachranBasah.1997. Ilmu Negara Pengantar Metode dan Sejarah Perkembangan.Bandung: P Citra Aditya Bakti

SjamsuddinHelius dan Ismaun. 1996. Pengantar Ilmu Sejarah. Jakarta: Proyek Pendidikan Tenaga Akademik

Soekanto, Soerjono.2013. Sosiologi Suatu Pengantar. Jakarta: Rajawali Pers

Suryabrata, Sumadi. 1997. Metodologi Penelitian. Jakarta: Raja Grafindo

Suyanto, Bagong, dkk. 2011. Metode Penelitian Sosial. Medan: Grasindo

Tohirin. 2012. Metode Penelitian Kualitatif. Jakarta: PT. Raja GrafindoPersada

Utomo, St. Laksono. 2016. Hukum Adat. Jakarta: Rajawali pers

Widagdho, Djoko, dkk. 1999. Ilmu Budaya Dasar. Jakarta : Pt. Bumi aksara

Zainal, VeithzalRivai, dkk. 2014. Kepemimpinan dan PerilakuOrganisas. Jakarta: Rajawali pers

Abdul Rahman N. 2014. Kampung DongiPotretPenerapanKebijakan Negara yang Mengakibatkan Penderitaan Masyarakat Adat. Sulawesi Selatan: Aliansi Masyarakat Adat Nusantara (AMAN Tanah Luwu)

Asrial, Fany.2012.Modal Sosial Pasitabe Sebagai Lembaga Adat Dalam ProsesKesejahteraan Masyarakat di KecamatanWasupondaKabupatenLuwu Timur. Makassar: skripsi Universitas Hasanuddin

Julianti. 2012. Kehidupan Sosial Dan Ekonomi Penduduk Asli Pasca Konversi Lahan Oleh Pt. Inco. Tbk ( StudiKasusDesaSorowakoKecamatanNuhaKabupatenLuwu Timur Provinsi Sulawesi Selatan ).Makassar :Skripsi Universitas Hasanuddin 